\title{
Effectiveness of Autologous Schwann Cell and Bone Marrow-Derived Mesenchymal Stem Cell Transplantation for Individuals With Spinal Cord Injury in Promoting Sensory Recovery
}

\author{
Maryam Golmohammadi $^{\circledR}$, Mohammadhosein Akhlaghpasand $^{1}{ }^{\circledR}$, Saeed Oraee-Yazdani ${ }^{*{ }^{(D}}$, Alireza Zali $^{(\mathbb{}}$ \\ ${ }^{1}$ Functional Neurosurgery Research Center, Shohada Tajrish Comprehensive Neurosurgical Center of Excellence, Shahid \\ Beheshti University of Medical Sciences, Tehran, Iran \\ ${ }^{2}$ Shohada Tajrish Neurosurgical Center of Excellence, Functional Neurosurgery Research Center, Shohada Tajrish Hospital, \\ Shahid Beheshti University of Medical Sciences, Tehran, Iran
}

\begin{abstract}
Background: In recent decades, improvement in sensory and motor function after spinal cord injury $(\mathrm{SCl})$ is a major treatment goal. Stem cell therapy has become a promising treatment strategy in the regeneration of central nervous system injuries.

Methods: We assessed the effectiveness of autologous Schwann cell (SC) and bone marrow-derived mesenchymal stem cell (MSC) for individuals with $\mathrm{SCI}$ in promoting sensory recovery. Five patients with a mean \pm SD age of $38.80 \pm 5.84$ years were enrolled in the study. The follow-up course was 12 months.

Results: We found sensory changes in two patients assessed by the American Spinal Injury Association's (ASIA's) impairment scale. Systemic complications were not observed during the course of the study.

Conclusion: There were no adverse finding after cell transplantation. Also we observed improvement in sensory score in two patients. It seems that the use of this combination of cell therapy may be effective; but large group studies with control group are required to clarify the effect of either cells. Keywords: Schwann cell; Bone marrow; Mesenchymal stem cell; Spinal cord injury; Sensory recovery.
\end{abstract}

\author{
*Correspondence to \\ Alireza Zali, \\ Shohada Tajrish Neurosurgical \\ Center of Excellence, \\ Functional Neurosurgery \\ Research Center, Shohada \\ Tajrish Hospital, Shahid \\ Beheshti University of Medical \\ Sciences, Tehran, Iran. \\ Tehran, 1988873554, Iran, \\ Tel \& Fax : +9821-22438023, \\ Email: a.zali@sbmu.ac.ir
}

Published online December 30, 2020

\footnotetext{
Citation: Golmohammadi M, Akhlaghpasand M, Oraee-Yazdani S, Zali A. Effectiveness of autologous schwann cell and bone marrowderived mesenchymal stem cell transplantation for individuals with spinal cord injury in promoting sensory recovery. Clin Neurosci J. 2021;8(1):10-13. doi:10.34172/icnj.2021.03.
}

\section{Introduction}

Spinal cord injury (SCI) is a highly damaging clinical condition with permanent and economic disabilities for patients and communities. Traumatic SCI is more prevalent in men aged 16-30 years. Therefore, improvement of patient's function after SCI becomes a considerable issue in recent decades. Despite the numerous medical treatments such as methylprednisolone and thyrotropinreleasing hormone, the motor and sensory impairments persist and have shown limited effectiveness for spinal cord recovery. ${ }^{1,2}$

A promising treatment strategy for injuries to the central nervous system is stem cell therapy. The Schwann cell (SC) is one of the important components of the peripheral nerve cell, that release brain-derived neurotrophic factor and provide an appropriate environment for axon renewal. ${ }^{3}$ Moreover, bone marrow-derived mesenchymal stem cells
(MSCs) secrete neuroprotective and immunomodulatory cytokines and could differentiate into a variety of cells. ${ }^{4}$ The combination of SCs and MSCs are essential to cover the mechanisms of spinal cord injuries. Many studies have proven the safety of MSC and SC transplantation in SCI. However, the results were widely limited.

Few clinical studies have been done to show the possible outcomes of combination therapy for the treatment of patients with SCI. ${ }^{78}$ In present study, we aimed to investigate the effectiveness of co-transplantation of autologous bone marrow MSCs and SCs in promoting sensory recovery in patients with SCI.

\section{Materials and Methods}

Study Design

Five patients (three women and two men) with a mean \pm SD age of $38.80 \pm 5.84$ years, were enrolled in the study.

(C) 2021 The Author(s). This is an open access article distributed under the terms of the Creative Commons Attribution License (http:// creativecommons.org/licenses/by/4.0/), which permits unrestricted use, distribution, and reproduction in any medium, provided the original work is properly cited. 
Among these patients, four patient had cervical and one of them had thoracic lesions due to road traffic accidents and fall from a height.

The eligibility criteria for the study was absence of brain disease or psychological disorders, no stenosis, tethering or compression in magnetic resonance images (MRIs) of the spinal cord taken at the beginning of the study. These patients were enrolled in our one-year follow-up study. All the patients received standard therapy for SCI injury such as required spinal surgery and regular rehabilitation programs.

During the follow-up course, we evaluated sensory changes using the International Standard of Neurological Classification for Spinal Cord Injury (ISNCSCI) scoring system (motor and sensory), developed by the American Spinal Injury Association (ASIA).

\section{Cell Isolation, Characterization, and Transplantation}

After the admission of the patients in the operation room under standard conditions, cell isolation and transplantation of autologous SCs and MSCs were done according to the protocol that we used in our previous study. ${ }^{9}$ In order to collect SCs, the sural nerve of the person was sliced into $2-\mathrm{mm}$ pieces and incubation method was done with collagenase $\left(1.4 \mathrm{U} \mathrm{mL}^{-1}\right.$; Sigma, St. Louis, MO, USA) and Dispase (2.4 $\mathrm{U} \mathrm{mL}^{-1}$; Sigma). After cleaning and washing the collagenase twice with DMEM/ F12 and mesh filtering method, the cells were treated and processed with DMEM/F12, without fetal bovine serum (FBS) for five days $\left(37^{\circ} \mathrm{C}, 5 \% \mathrm{CO}_{2}\right)$. Then, during one week the concentration and extraction of FBS (Gibco) was increased in the culture to up to $10 \%$. S-100 and P-75 immunocytological staining was used to characterized the separated cells in our study.

For separating and isolating bone marrow stem cells (BMSCs), bone marrow blood (100e150 mL) was obtained from the iliac bone. Then, the bone marrow blood was centrifuged (400 g for 40 minutes) and the mononuclear cell layer was regained from the gradient under a compression split by Ficoll (1.077 g/L, Sigma) at a range of 1:3. The potency and power of the isolated cells were assessed by their capability to differentiate to adipogenic and osteogenic cells.

The MSCs and SCs were cultured separately in the environment, and a composition of isolated cells composed of MSCs at a final concentration of $1 \times 10^{6}$ cells per $\mathrm{mL}$ and SCs at a final concentration and density of $1 \times 10^{6}$ cells per $\mathrm{mL}$ (total volume of $2 \mathrm{~mL}$ ) was prepared.

To transplant cells, patients were hospitalized and entered in the course (approximately 2 weeks after biopsy). Then, we transplanted the cells into the L4/L5 level through lumbar puncture using a $24 \mathrm{G}$ spinal needle.

\section{Results}

Cells isolated from the sural nerve were positive for S-100 and P-75 markers, which indicated that these cells had properties of SCs. Also, MSCs were able to differentiate to adipogenic and osteogenic cells and were positive for CD73, CD90, and CD 105 and negative for CD45 in flow cytometry analysis.

Systemic complications such as fever, anaphylactic shock, hypersensitivities, rush or inflammation were not observed. Infectious complications such as meningitis and other complications associated with transplantation were absent. All five patients had their regular rehabilitation before and after transplantation and we evaluated their sensory and motor changes in 6,12, 18 and 24 months after surgery with ASIA scoring system.

Patient number 1 had grade B ASIA Impairment Scale (AIS) in C5 and C6 vertebrae. Before injection, ASIA score for sensory system was 16 . After transplantation we detected sensory change, and, according to our followup, the patient claimed to have improvement in the sense of pressure. The second patient had improvement at the sensory level after the injection. He had type A AIS before injection and his sensory score based on ASIA criteria was 29 for the right side and 29 for the left side (both sides up to T8). Four months later, he improved 11 points on each side and reached 40 (L1 sensory level). The third patient, who had a type A AIS in the 6th and 7th vertebrae of the cervix, had no change in his sensory level. In the remaining patients, no progress was found in sensory scores according to ISNCSCI criteria (Table 1). We also detected paresthesia and muscle spasm in some patient after cell injection (Table 2).

\section{Discussion}

We found that combination of autologous SC and bone marrow-derived MSC transplantation could promote sensory score in some patients with SCI and there were no

Table 1. Demographic and Clinical Features of the Patients

\begin{tabular}{|c|c|c|c|c|c|c|c|c|}
\hline Patients & Sex & Age (y) & $\begin{array}{l}\text { Interval Before } \\
\text { Injection (month) }\end{array}$ & Cause of Injury & Injury Site & $\begin{array}{l}\text { Sensory Status Before } \\
\text { (Right-Left) }\end{array}$ & $\begin{array}{c}\text { Sensory Status After (Right- } \\
\text { Left) }\end{array}$ & $\begin{array}{l}\text { ASIA } \\
\text { Grade }\end{array}$ \\
\hline 1 & Female & 58 & $1(25 d)$ & Accident & C5, C6 & $16-16$ & $56-56$ & B \\
\hline 2 & Male & 20 & 12 & Accident & $\mathrm{T} 7, \mathrm{~T} 8$ & $29-29$ & $40-40$ & A \\
\hline 3 & Male & 55 & 6 & Falling & $\mathrm{C} 6, \mathrm{C} 7$ & $34-34$ & $34-34$ & A \\
\hline 4 & Female & 34 & 3 & Accident & $\mathrm{C} 8$ & $36-36$ & $36-36$ & A \\
\hline 5 & Female & 30 & 12 & Falling & $\mathrm{C} 5$ & $28-20$ & $28-20$ & A \\
\hline
\end{tabular}


Table 2. Subjective changes in SCl patients

\begin{tabular}{|c|c|c|c|c|c|c|c|}
\hline \multicolumn{8}{|c|}{ Pre-cell Transplantation } \\
\hline Patients & 1 & 2 & 3 & 4 & 5 & 6 & 7 \\
\hline Neuropathic pain & + & + & - & - & - & - & - \\
\hline Paresthesia & + & + & - & - & - & - & - \\
\hline Muscle spasm & + & + & - & - & - & - & - \\
\hline \multicolumn{8}{|c|}{ Post-cell Transplantation } \\
\hline Patients & 1 & 2 & 3 & 4 & 5 & 6 & 7 \\
\hline Neuropathic pain & + & + & - & - & - & - & + \\
\hline Paresthesia & + & + & - & - & - & + & + \\
\hline Muscle spasm & + & + & - & - & - & - & + \\
\hline
\end{tabular}

systemic complications after autologous transplantation. Stem cell therapy is an attractive and promising treatment strategy for spinal cord regeneration because numerous changes occurring in spinal cord tissue after injury, need a combination cell therapy to provide axonal regeneration promotion and rehabilitation. ${ }^{10}$ Many trials have been performed and applied SCs and MSCs alone for spinal cord regeneration. ${ }^{5,11-13}$ MSCs have an important role in cell treatment because of low immunogenicity and their ability to differentiate and secrete neuroprotective cytokines which can increase neural regeneration. ${ }^{12}$ SCs are able to guide neurite outgrowth, axonal surviving and remyelination. ${ }^{14}$

As mentioned above, recently, combination therapies have attracted attention for spinal cord regeneration. Although the safety and feasibility of these combination has been studied, the results were widely limited. ${ }^{9,15}$ Kakabadze and colleagues found improvement of motor and sensory functions of various degrees in $50 \%$ cases after BMSC transplantation and they indicated that the transplantation of mononuclear-enriched autologous BMSCs is a feasible and safe technique. ${ }^{16}$ Others reported that thirty days after transplantation, 15 patients (75\%) demonstrated significant improvements in sensory, motor, and autonomic nerve function. ${ }^{17}$

Our results showed that cell transplantation improved sensory score in two patients as assessed by the ASIA impairment scale. Yazdani and colleagues reported that ASIA class in one patient changed from A to B, in addition to the improvement in indexes of urodynamic study, especially bladder compliance. ${ }^{8}$

In our study, systemic complications such as fever, Anaphylactic shock, hypersensitivities, rush or inflammation was not observed which may suggest the safety of this cell transplantation. In accordance with our results another study indicated that there were no adverse findings at least 2 years after autologous transplantation of SC and MSCs combination into the injured spinal cord. ${ }^{9}$

Our study had several limitations. First was the small sample size, which might affect the observed correlations.
Second, further large group studies with control group are required to clarify the effect of either cells.

\section{Conclusion}

There were no adverse finding after cell transplantation. Also we observed improvement in sensory score in two patients. It seems that the use of this combination of cell therapy may be effective; but large group studies with control group are required to clarify the effect of either cells.

\section{Conflict of Interest}

The authors declare that they have no conflict of interests.

\section{Acknowledgments}

The authors would like to thank Shahid Beheshti University of Medical Sciences, Tehran, Iran for their support and assistance with this research.

\section{Ethical Statement}

This study was approved by the Institutional ethics committee of Shahid Beheshti University of Medical Sciences and was conducted in accordance with Declaration of Helsinki.

\section{References}

1. Willison AG, Smith S, Davies BM, Kotter MRN, Barnett SC. A scoping review of trials for cell-based therapies in human spinal cord injury. Spinal Cord. 2020;58(8):844-56. doi: 10.1038/s41393-020-0455-1.

2. Wyndaele M, Wyndaele JJ. Incidence, prevalence and epidemiology of spinal cord injury: what learns a worldwide literature survey? Spinal Cord. 2006;44(9):523-9. doi: 10.1038/sj.sc.3101893.

3. Bond AM, Ming GL, Song $\mathrm{H}$. Adult mammalian neural stem cells and neurogenesis: five decades later. Cell Stem Cell. 2015;17(4):385-95. doi: 10.1016/j.stem.2015.09.003.

4. Malgieri A, Kantzari E, Patrizi MP, Gambardella S. Bone marrow and umbilical cord blood human mesenchymal stem cells: state of the art. Int J Clin Exp Med. 2010;3(4):248-69.

5. Saberi H, Moshayedi P, Aghayan HR, Arjmand B, Hosseini SK, Emami-Razavi SH, et al. Treatment of chronic thoracic spinal cord injury patients with autologous Schwann cell transplantation: an interim report on safety considerations and possible outcomes. Neurosci Lett. 2008;443(1):46-50. doi: 10.1016/j.neulet.2008.07.041.

6. Thomspon M, Wolfe D, Champagne J, Mei S, Lalu M, Fergusson D, et al. Safety of cell therapy with mesenchymal stromal cells): an updated systematic review and meta-analysis of randomized controlled trials (SafeCell update). Cytotherapy. 2018;20(5):S53-S4. doi:10.1016/j.jcyt.2018.02.146

7. Liau LL, Looi $\mathrm{QH}$, Chia WC, Subramaniam T, Ng MH, Law JX. Treatment of spinal cord injury with mesenchymal stem cells. Cell Biosci. 2020;10(1):112. doi: 10.1186/s13578-02000475-3.

8. Oraee-Yazdani S, Hafizi M, Atashi A, Ashrafi F, Seddighi AS, Hashemi SM, et al. Co-transplantation of autologous bone marrow mesenchymal stem cells and Schwann cells through cerebral spinal fluid for the treatment of patients with chronic spinal cord injury: safety and possible outcome. Spinal Cord. 2016;54(2):102-9. doi: 10.1038/sc.2015.142.

9. Oraee-Yazdani S, Hafizi M, Zali AR, Atashi A, Ashrafi F, 
Seddighi AS, et al. Safety and possible outcome assessment of autologous Schwann cell and bone marrow mesenchymal stromal cell co-transplantation for treatment of patients with chronic spinal cord injury. Cytotherapy. 2013;15(7):782-91. doi: 10.1016/j.jcyt.2013.03.012.

10. McCreedy DA, Sakiyama-Elbert SE. Combination therapies in the CNS: engineering the environment. Neurosci Lett. 2012;519(2):115-21. doi: 10.1016/j.neulet.2012.02.025.

11. Xu P, Yang X. The efficacy and safety of mesenchymal stem cell transplantation for spinal cord injury patients: a meta-analysis and systematic review. Cell Transplant. 2019;28(1):36-46. doi: 10.1177/0963689718808471.

12. Yoon SH, Shim YS, Park YH, Chung JK, Nam JH, Kim MO, et al. Complete spinal cord injury treatment using autologous bone marrow cell transplantation and bone marrow stimulation with granulocyte macrophage-colony stimulating factor: phase I/II clinical trial. Stem Cells. 2007;25(8):2066-73. doi: 10.1634/stemcells.2006-0807.

13. Bhanot Y, Rao S, Ghosh D, Balaraju S, Radhika CR, Satish Kumar KV. Autologous mesenchymal stem cells in chronic spinal cord injury. Br J Neurosurg. 2011;25(4):516-22. doi:
10.3109/02688697.2010.550658.

14. Schaal SM, Kitay BM, Cho KS, Lo TP Jr, Barakat DJ, Marcillo $A E$, et al. Schwann cell transplantation improves reticulospinal axon growth and forelimb strength after severe cervical spinal cord contusion. Cell Transplant. 2007;16(3):207-28. doi: 10.3727/000000007783464768.

15. Kakabadze Z, Kipshidze N, Mardaleishvili K, Chutkerashvili G, Chelishvili I, Harders A, et al. Phase 1 trial of autologous bone marrow stem cell transplantation in patients with spinal cord injury. Stem Cells Int. 2016;2016:6768274. doi: 10.1155/2016/6768274.

16. Jiang PC, Xiong WP, Wang G, Ma C, Yao WQ, Kendell SF, et al. A clinical trial report of autologous bone marrow-derived mesenchymal stem cell transplantation in patients with spinal cord injury. Exp Ther Med. 2013;6(1):140-6. doi: 10.3892/ etm.2013.1083.

17. Jiang $\mathrm{PC}$, Xiong $\mathrm{WP}, \mathrm{Wang} \mathrm{G}$, et al. A clinical trial report of autologous bone marrow-derived mesenchymal stem cell transplantation in patients with spinal cord injury. Exp Ther Med. 2013;6(1):140-146. doi:10.3892/etm.2013.1083. 